\title{
DIEGO DIAZ DE LISBOA, CANTERO Y ARQUITECTO DEL VIRREY MENDOZA
}

\author{
por Juan Miguel SerRera
}

\begin{abstract}
Se trata del primer estudio de carácter monográfico que se realiza sobre Diego Díaz de Lisboa, un cantero y arquitecto portugués que, tras pasar por Sevilla en 1526, trabaja en México desde 1530 hasta 1562. Descubrió canteras y enseñó el arte de cantería a los indígenas, interviniendo en las grandes obras públicas que se ejecutan en la ciudad de México durante el gobiemo del Virrey Mendoza.

This is the first monographic study that has been realized about Diego Díaz de Lisboa, a portuguese stonemason and architect, which passed by Seville in 1526. Then he went to México where he worked between 1530 and 1562 . He discovered quarries and teached the quarrying art to the natives. He collaborated in the most important public works, which were done in México City during the governement of Viceroy Mendoza.
\end{abstract}

Diego Díaz de Lisboa fue uno de los maestros que conformaron el panorama de la todavía no bien conocida arquitectura mexicana del segundo cuarto del siglo XVI. Hasta ahora su figura no había suscitado la elaboración de un rabajo de carácter monográfico. En realidad así debía de ser, ya que los pocos datos que de él se tenían no lo diferenciaban de los otros maestros. Conocido, sobre todo, por su trabajo como cantero, no parecía, en principio, que hubiera abordado la ejecución de obras de cierta envergadura, razón por la cual, se citaba, sin más, entre los canteros que trabajaron en México durante el segundo cuarto del siglo XVI. De hecho, se mencionaba por haber labrado en 1535 una de las ventanas del Hospital de Jesús y por constar que había enseñado el arte de la cantería a los indígenas. A esos datos habrá que sumar a partir de ahora los contenidos en los documentos que han dado origen a este trabajo: la pobranza de méritos y servicios hecha a su instancia en 1562 por la Real Audiencia de la Nueva España y la 
carta por él enviada ese mismo año al príncipe de Eboli, escritos localizados en la Sección dedicada al Consejo y Juntas de Hacienda del Archivo General de Simancas '. También habrá que tener en cuenta los recogidos en una anterior probanza, de la que Marco Dorta dio escueta noticia y cuya atenta lectura ha servido para completar la información aportada por los documentos antes cita$\operatorname{dos} 2$.

Sumando todos esos datos a los ya conocidos es posible reconstruir, si bien a grandes rasgos, su biografía y estudiar, aunque sea fragmentariamente, su producción, que abarcaba tanto obras de cantería como de arquitectura. Entre ellas destacan las que debió ejecutar como Maestro Mayor de la primitiva catedral de México y las que realizó como Oficial de las obras públicas de esa ciudad, cargos cuyo ejercicio justificaría, de por sí, que se le dedicasen estas páginas.

\section{UN PORTUGUES EN LA NUEVA ESPAÑA}

La fecha de su nacimiento se deduce de lo dicho por el propio Díaz en la información abierta en 1550 por la Audiencia de la Nueva España a petición del convento de Santo Domingo. Al declarar como testigo aseguró tener sesenta años, dato del que se deduce que nació en $1490^{3}$. La luz la vio por primera vez en Lisboa, ciudad cuyo nombre asumió como segundo apellido. De esa forma, como Diego Díaz de Lisboa, encabezó la carta que el 15 de abril de 1562 envió a Ruy Gómez de Silva, el todopoderoso príncipe de Eboli, a quién por ser también portugués y haber llegado a España formando parte del séquito de la emperatriz Isabel se dirige como un compatriota que en sus años mozos también estuvo vinculado con la corte portuguesa. Se le presentó como criado del señor Vasco Eanes Corte Real, Veedor que fue de la Casa del Rey Don Manuel de Portugal, quien como tal tuvo a su cargo todo lo concerniente a las obras reales; circunstancia ésta que explica que Díaz se presentara como su criado y que señalara que su suegro, Juan Alvarez, también lo había sido. Para congraciarse con el príncipe y obtener sus favores le hizo saber que había visto nacer a la Emperatriz, afirmación que hay que matizar, ya que posiblemente lo que quería dejar claro es que ya por entonces estaba relacionado con el mundo de la Corte. Aunque da por hecho que el príncipe no lo conocía, le dice haberlo visto en dos ocasiones,

1. Archivo General de Simancas. Consejo de Juntas y Hacienda. 45-200. Debo la noticia de estos documentos a mi buen amigo el Profesor Fernando Bouza, a quien agradezco la información.

2. MARCO DORTA, Enrique: Fuentes para la Historia del Arte Hispanoamericano. Estudio y Documentos, vol. I, Sevilla, 1951, p. 13, nota núm. 2. La probanza citada por Marco Dorta se localiza en el Archivo General de Indias, México, 207.

3. Ibidem, pp. 1-2 y 96-98. 
asociando esos encuentros a la figura de la Emperatriz. La primera fue en Lisboa, cuando su señor fue a visitar a la por entonces todavía infanta portuguesa. Allí estaba Ruy Gómez de Silva, hablando, le recuerda, con Don Rodrigo, el Mayordomo de la Infanta. La segunda fue en Sevilla, precisando Díaz en este caso el año, 1526, y aún, si bien indirectamente, la fecha exacta, ya que dice haberlo visto cuando la Emperatriz entró en esa ciudad para desposarse con el Emperador, evento acaecido el 3 de mayo de $1526^{4}$.

Constatada la presencia de Díaz en Sevilla en 1526, se ignoran los motivos que le llevaron a abandonar Lisboa. No obstante, es posible que lo hiciera para trasladarse a América, razón por la cual se explica su paso por Sevilla. Con respecto a las motivaciones que le pudieron llevar a cruzar el Atlántico, no parece que deban desvincularse de la figura de su señor, Corte Real. Este último era hijo de Joâo Vaz Corte Real, el mítico descubridor de Terra Nova, habiendo sucedido a su padre en la capitanía de las Azores. Dada la vocación atlántica de los Corte Real, no debe sorprender que Díaz decidiera marcharse a las Indias. El paso le debió resultar lógico, ya que si por entonces esas lejanas tierras se presentaban como una nueva tierra de promisión, para él, como cantero, se ofrecerían como el campo más idóneo para ejercer su arte. Al respecto debió de verse favorecido por la liberación general del control migratorio imperante en esos años, en los que, siguiendo las directrices aperturistas del Emperador, se permitió el establecimiento en ultramar de gentes a las que hasta entonces les estaba vetado, entre otros los portugueses. En la carta enviada al príncipe hace referencia exacta al año en que pasó a la Nueva España: 1526. Esa fecha concuerda con lo declarado años más tarde, ya que en 1546 dijo haber llegado hacía unos veinte años. Asimismo, indica la flota en que se fue: aquella que llevó a Don Luis Ponce de León, a quién Carlos $\mathrm{V}$ encargó tomar juicio de residencia a Hernán Cortés 5 .

Desde 1526 en la Nueva España, hasta 1530 no está documentada su presencia en la capital del Virreinato, ignorándose por ahora las localidades en que pudo trabajar durante esos años. El 18 de julio de 1530 recibe la carta de vecindad del Cabildo mexicano, concediéndosele ese mismo día un solar en la calzada

4. La Emperatriz entró en Sevilla el 3 de marzo de 1526, haciéndolo el Emperador el 10 de ese mismo mes y año. Celebrada la boda la noche del 10 al 11, permanecieron en Sevilla hasta el 13 de mayo, fecha en que emprendieron viaje a Granada. Al respecto, véase CARRIAZO Y ARROQUIA, Juan de Mata: "La boda del Emperador. Notas para una historia del amor en el Alcázar de Sevilla", Archivo Hispalense, núms. 93-94, vol. XXX, Sevilla, 1959, pp. 9-108.

5. Sobre el citado juicio, cfr. GARCIA-LOMMAS JUNG, Cristina: "Notas sobre el juicio de residencia de Hemán Cortés", en Hernán Cortés y su tiempo, Ontinyent, Valencia, 1987, pp. 235243. 
por entonces denominada de Ixtapalapa 6 . Allí debió vivir hasta su muerte, acaecida con posterioridad a 1562, fecha en que, cumplidos setenta y cinco años, todavía seguía solicitando el pago de los haberes que suscitaron la probanza y la carta enviadas al príncipe de Eboli en 1562.

Esos documentos se redactan contando Díaz setenta y dos años. Por entonces se encontraba viejo y cansado, enfermo de gota y falto de vista, razón por la cual se temía que en unos días no podría sustentarse honestamente. El problema lo agravaban sus cinco hijos, que de forma expresa cita como bastardos. Al respecto, y teniendo en cuenta que antes había hecho mención de su suegro, lo más lógico es pensar que formó en México una segunda familia, paralela a la establecida canónicamente en Portugal, fenómeno corriente entre los conquistadores. Así se deduce del hecho de que en 1546 figurase en una relación de "solteros e biudos que dizen tener sus mugeres en Spaña" 7 .

Para resolver lo angustioso de su situación, ruega al príncipe que le restituyeran la encomienda del pueblo de Chiconautla, objetivo primordial de su carta y razón de ser de las pobranzas. A fin de que el príncipe se interesara por su caso, recurre una vez más al hecho de que los dos eran portugueses, tema que le lleva a plantearle la situación en que se encontraban sus compatriotas en aquel Virreinato. Para los castellanos, le dice, los portugueses eran lo peor, siendo considerados gente poco honrada. Por ello, se sentían apocados, no hallándose como entre sus parientes y naturales. Aunque el pañorama así descrito no se atuviera en todo a la realidad, lo expuesto por Díaz sirve para poner de relieve la progresiva jerarquización y diversificación de la sociedad colonial, confirmando, una vez más, la consolidación de la población castellana como el grupo rector de esa sociedad. Partiendo de esa realidad, le pide que interceda ante el Rey, rogándole que actuase como en su día lo hicieron Raquel ante el faraón y Esther en Babilonia, quienes mediaron en favor de los "indios hebreos". Si así se comportaron esas figuras con los judíos, ¿qué no podía hacer por él el de Eboli, si además él era cristiano y, sobre todo, su compatriota? Al dirigirse en esos términos al príncipe, Díaz no sólo demostraba sus conocimientos bíblicos, sino que dejaba traslucir el mesianismo imperante por entonces en el Virreinato, en el que, según Mendieta,

6. TOUSSAINT, Manuel: Arte colonial en México, México, 1948, pp. 28 y 254, nota núm. 4. (Se cita por la edición de 1974). En el cabildo celebrado el 27 de febrero de 1537 se le concedió una ampliación del solar, obligándosele a edificarlo, o al menos cercarlo, en el plazo de un año. Al respecto, cfr. Actas de Cabildo de la ciudad de México, vol. III, p. 74. (Se cita por la edición del "Municipio Libre," publicada por Ignacio Bejarano, México, 1889-1911, 50 vols.).

7. ICAZA, Francisco de: Diccionario autobiográfico de conquistadores y pobladores de Nueva España, vol. II, Madrid, 1923, p. 310. En la carta enviada al príncipe, Díaz señala que tenía cinco hijos, de los cuales tres eran varones. El mayor hacía tres años que se había ido al Perú y no sabía si vivía o no. El menor, que envía como criado al Príncipe, se llamaba José. 
Hernán Cortés había actuado como un "enviado de Dios, como otro Moisés, para liberar a los naturales de la servidumbre de Egipto" 8 .

Su petición se centraba en la restitución de la encomienda de Chiconautla, pueblo situado al norte de la ciudad de México perteneciente a la Corona que le había venido proporcionando de 500 a 600 ducados por año. Esa encomienda se la debieron conceder recién llegado a la Nueva España, ya que el 17 de mayo de 1532 revirtió a la Corona ${ }^{9}$. Mientras tanto, le rogaba la merced de 100 pesos por año, cantidad similar a la que en su día le concedió el Emperador ${ }^{10}$. No habiéndolos cobrado aún en el momento de firmar la carta -de hecho no lo recibió hasta el 23 de mayo de $1565^{11}$ y no habiéndole contestado el príncipe a una anterior misiva -enviada, le dice, a través de Don Antonio de Turcios-, puso todo su empeño en que los documentos que ahora le enviaba llegasen a sus manos. Desconfiando de los cauces legales, por medio de los cuales hizo llegar al Consejo de Indias la probanza conservada en el Archivo de Indias, se los mandó a través de Antón Pérez de Silva, un portugués residente en México que se decía pariente muy allegado del de Eboli. Para garantizar que los recibiría y para asegurar al menos el porvenir de uno de sus hijos, le envía el menor, con el ruego de que lo acogiese como criado. Dando por hecho de que en esa ocasión sí le contestaría, se atreve a sugerirle la forma en que debería hacerle llegar su respuesta, sirviendo su indicación para mostrar la realidad de la administración colonial. Le ruega se la enviase a través del mismo Antón Pérez de Silva, para que de esa forma no cayera en manos del Virrey -en 1562 Don Luis de Velasco-, al que textualmente califica como "enemigo de pobres". También le pide que los documentos vinieran firmados por él y, sobre todo, por el Rey, ya que había visto que ni los virreyes, ni los presidentes de la audiencia, ni los oidores llevaban a término lo dispuesto en las reales cédulas.

8. BORGES MORAN, Pedro: “Mesianismo, conquista y evangelización en Hernán Cortés”, en Hernán Cortés y su tiempo, op. cit., pp. 461-474.

9. GERHARD, Peter: A guide to the historical geography of New Spain, Cambridge, 1972, p. 226. En 1546 Díaz dice que se "le encomendó el pueblo de Chiconautla, el qual le fue removido sin causa alguna". Por ello "pide que se le buelba el dicho pueblo o se le de corregimyento, y en el rrepartimiento se tenga dél memoria". Cfr. ICAZA, Francisco de: Diccionario autobiográfico, op. cit., vol. II, núm. 1.272, p. 310.

10. De esos 100 pesos, los dos primeros tercios los recibió durante el gobiemo del Virrey Mendoza, cobrando el último el 17 de junio de 1553, bajo el gobierno del Virrey Velasco. Cfr. TOVAR DE TERESA, Guillermo: La ciudad de México y la utopía en el siglo XVI, México, 1987, p. 170 .

11. Ibidem. 


\section{UN CANTERO ARQUITECTO}

Junto a la carta le envía la pobranza incoada ante la Real Audiencia de la Nueva España. Su apertura la solicitó el 6 de febrero de 1562, habiendo pedido la anterior el 19 de enero de ese mismo año. En la primera actuaron de oficio como testigos Antonio Velázquez Narváez, Pedro de Solís, Manuel López y el canónigo de la catedral mexicana Diego Velázquez, declarándose todos ellos "vecinos y conquistadores de esta cibdad". En la segunda testificación Juan de Cuevas, Diego de Zamora, y Sancho López de Agurto, escribanos y vecinos de la ciudad de México. En ambos casos sus declaraciones se atuvieron a lo contenido en un interrogatorio de siete preguntas, subdivididas, a su vez, en tres puntos cada una, centrándose las preguntas en cuestiones de índole profesional.

Por medio de las dos primeras se intentó probar que los testigos lo conocían y que era verdad que había pasado a la Nueva España hacía unos cuarenta años. En ese orden de cosas las respuestas fueron unánimes, precisando uno de ellos que lo conocía hacía más de treinta y cinco años y que había oído decir que llegó con Don Luis Ponce de León. Más interés tienen otros puntos, en concreto los relativos a si les constaba que era cantero, si lo habían visto trabajar como tal y si era verdad, como él decía, que había enseñado a los indígenas el arte de la cantería.

Esas preguntas tendían a confirmar la veracidad de lo expuesto por Díaz ante la Audiencia. En ese orden de cosas su declaración discurrió en términos parecidos a como meses más tarde expuso su caso al príncipe. Consciente de su propia valía, no dudó en decirle que era "el maestro de cantería y arquitectura de más provecho de los que pasaron a la Nueva España", añadiendo que había sido de los primeros en ese arte en llegar. Asimismo, le informó que se lo había enseñado a los indígenas, formándose con él numerosos maestros y oficiales indios de ese arte. Como en otros puntos su declaración se vio confirmada por los testigos. Uno de ellos declaró que en verdad era maestro de cantería, añadiendo que el mejor de los que habían llegado y, por supuesto, el mejor de cuantos conocía. Otro de los testigos, por su parte, precisó que era maestro examinado. Al respecto no hay porqué dudar de su testimonio, si bien lo más probable es que el examen lo pasara en España o, lo que parece más lógico, en Portugal. Así parece deducirse del hecho de que hasta 1599 no se aprobaran en la Nueva España las primeras Ordenanzas de Albañilería, por las que a partir de entonces también se rigieron los arquitectos y los canteros 12 .

Lo que sí parece evidente es que Díaz recibió en su día el nombramiento de Maestro Mayor de las obras de cantería de la Nueva España. Así se menciona en

12. FERNANDEZ, Martha: Arquitectura y gobierno virreinal. Los maestros mayores de la ciudad de México. Siglo XVII. México, 1985, pp. 29 y 287-291. 
los documentos, entre otros el expedido en 1565 por la Real Audiencia concediéndole el pago de lo que aún le debían. Por entonces, sin embargo, ya no ostentaba ese cargo, ya que se le cita como "Maestro que ha sido de las obras de cantería de esta Nueva España". Por ahora se ignora la fecha en que recibió ese nombramiento, si bien todo hace suponer que fue al poco tiempo de llegar a la Nueva España. Si a ese cargo iba vinculado, como él dice, la encomienda de Chiconautla, debió ostentarlo hasta el 17 de mayo de 1532, fecha en que esa encomienda revirtió a la Corona. Precisamente por esos años dijeron dos de los testigos que había sido Maestro Mayor de las obras de cantería, ya que atestiguaron que lo fue en tiempo del licenciado Salmerón y del Obispo de Santo Domingo, dato este último que marca el año de 1534 como fecha tope para su desempeño.

En cuanto a si Díaz había enseñado el arte de la cantería a los indígenas, "amostrandolo a muchos yndios de esta tierra", todos los testigos afirmaron ser cierto. Uno precisó que "les a dado regla y compás", añadiendo otro que los había visto trabajar en obras en las que él era el maestro. De esa forma se confirmaba lo declarado en 1546: "que todos los yndios que al presente son oficiales de cantería lo son por su yndustria". Por desgracia, los testigos no aportaron más datos sobre el tema, no pudiéndose profundizar a partir de la documentación que se analiza en el estudio de la formación artística de los indígenas ${ }^{13}$. De todas formas, cabe hacer algunas consideraciones. Sus enseñanzas se encuadran dentro de la política evangelizadora de la Iglesia, llevada a cabo, en especial, a través de las ordenes religiosas. En ese sentido, y teniendo en cuenta que al menos desde 1530 esta documentada su presencia en la antigua Tenochtitlan, hay que señalar que sus enseñanzas corrieron paralelas a las impartidas por los franciscanos, en México desde 1524. Al respecto, es más que probable que colaborara con Fray Juan de Zumárraga, ya que, como señala más adelante en la pobranza, fue Maestro Mayor de la primitiva catedral de México.

Del cómputo de los años en que Díaz estuvo instruyendo artísticamente a los indígenas se desprende una segunda consideración. Se le puede, y se le debe, citar como cantero del Virrey Mendoza, cuyo interés por formar artísticamente a los indígenas fue coincidente al mostrado por el obispo Zumárraga. De ese interés da muestra en la Memoria de Gobierno que dirige a su sucesor, el Virrey Velasco, en la que textualmente le dice que ha "procurado que haya oficiales indios en esta República, e así viene a haber gran cantidad de ellos". Uno de los

13. Sobre el particular, consúltense los trabajos de GARCIA SAIZ, M. a Concepción: "La formación artística del indígena en la Nueva España" y de MARCO DORTA, Enrique: "Los indígenas y las artes en el siglo XVI", en Estudios sobre política indigenista española en América, vol. III, Valladolid, 1977, pp. 321-342 y 345-353. 
maestros que siguiendo sus directrices se dedicó a enseñar el arte de la cantería a esos indios fue Díaz, precisándose en la pobranza algunas de las obras en las que intervinieron.

Esas obras, en las que los indígenas no sólo actuaron como simples peones, sino, como señalan los testigos, también como oficiales y, aún como maestros, se conocen gracias a las declaraciones de los testigos. No obstante, hay que señalar que su estudio no podrá ser completo, ya que, dada la naturaleza jurídica del documento en que se reseñan, su descripción fue muy somera. Al respecto es significativo que ni Díaz ni los testigos aportasen datos precisos sobre las canteras "que por yndustria del dicho Díaz se han descubierto", "de las que al presente (1562) se probee esta ciudad de piedra". Los testigos afirmaron que Díaz fue quién las descubrió, pero ninguno dijo cuando ni señaló su nombre. Uno, sin embargo, precisó que se encontraban a cinco leguas de la ciudad de México y que de ellas se surtía por entonces la catedral. Posiblemente serían las canteras de cuyo descubrimiento trató el Cabildo el 22 de diciembre de 1533, ya que las de Tenayuca, cuya inspección se ordenó al Maestro Mayor de la ciudad en el cabildo celebrado el 30 de junio de 1547, se encuentran al sur de Puebla ${ }^{14}$. De todas formas, el dato es de por sí significativo. Demuestra que Díaz llegó a la Nueva España formado como cantero, debiendo de haber aplicado en esas tierras los conocimientos puestos en práctica con anterioridad en Lisboa y, quizás, en Sevilla.

Con las piedras sacadas de esas canteras construiría la acequia, los puentes y las alcantarillas que se citan en las informaciones, así como el caño que traía el agua desde Chapultepec y la fuente situada en la Plaza Mayor; obras realizadas, según los testigos, de acuerdo a su "yndustria". La acequia se describe como la que "pasa por medio e junto a la placa de esta ciudad de una parte a la otra". De esa acequia -recogida gráficamente en los planos de la Plaza Mayor publicados por Angulo, fechable uno entre 1562 y 1566 y otro en 1596 15_ dice uno de los testigos "que al tiempo que se hizo la acequia que pasa por la placa por la cual vienen muchos bastimentos a esta ciudad vido que el dicho Diego Díaz fue el maestro de la dicha obra dende el principio della en tiempo del señor visorrei don antonio de mendoça y que el dicho Diego Díaz trabajo mucho en ello en dar la yndustria a la gente e yndios que la hizieron, e que de ello susodicho se a seguido mucho probecho a la República por ser el principal servicio que la ciudad tiene". Pese a lo dicho por los testigos, no está claro que esas obras se hicieran de

14. Actas de Cabildo, op. cit., vols. III y IV, pp. 66 y 183.

15. ANGULO INIGUEZ, Diego: Planos de monumentos arquitectónicos de América y Filipinas, vol. I, Sevilla, 1939, pp. 16-25, láminas 2-A a 2-E.

16. Actas de Cabildo, op. cit., vols. II y V, pp. 178 y 179. 
acuerdo a su "yndustria". Con respecto al caño que traía el agua desde Chapultepec, las noticias son contradictorias. En el cabildo celebrado el 16 de agosto de 1555 se acordó encomendárselo a Juan Gallegos. Ello no implica que Díaz no trabajara en él. Lo más probable es que interviniera en su ejecución, pero como cantero, no como responsable principal, papel reservado a Gallegos. Lo mismo debió sucederle con el caño abierto en 1532. Si intervino en él, lo haría también como colaborador, ya que la dirección se la encomendó el Cabildo el 6 de mayo de 1532 a los canteros Maestre Martín y Rodrigo de Pontecillas 16. Con respecto a la fuente, aunque uno de los testigos precisó que se ejecutó de acuerdo a sus trazas, no parece que fuera así. La primitiva la labró con anterioridad a 1527 Juan de Entrambas Aguas, indicando otro de los testigos que por entonces estaba a cargo de Claudio de Arciniega.

La simple enumeración de esas obras sirve para poner de relieve que Díaz no sólo desempeñó las tareas propias de un Maestro Mayor de obra de cantería, sino que también intervino en obras propias de los Alarifes de la ciudad, o Alarifes de obras, y, aún, de los denominados a partir de 1602 Maestros de aguas, a cuyo cargo estuvo todo lo relacionado con los acueductos, las cañerías y los desagües de la ciudad 17. De hecho, uno de los puntos que con más insistencia quiso probar es el de que había sido Maestro Mayor de las obras públicas de la ciudad. Por desgracia, los testigos no pudieron confirmar su aserto, ya que el que más datos aportó sólo pudo decir que lo había oído comentar. Declarando bajo juramento, difícilmente podrían haber dicho otra cosa. Consultadas las Actas de Cabildo correspondientes a los años que van desde 1530 hasta 1562 , se comprueba que Díaz nunca desempeñó ese puesto. El 8 de noviembre de 1531 se nombró para ese cargo a Juan de Entrambas Aguas, ostentándolo hasta el 14 de septiembre de 1540, fecha en que lo sustituyó Juan Franco. Tampoco parece ser que hubiera recibido el nombramiento de Obrero Menor de las obras públicas de la ciudad, puesto desempeñado por Antón García Saldaña, quién tras el fallecimiento de Franco, el 31 de agosto de 1554 solicitó sucederle en el puesto de Maestro Mayor 18. A tenor de la documentación hasta ahora publicada, Díaz sólo fue Oficial de las obras públicas de la ciudad, evidenciándolo así el que al declarar como testigo de la información pedida en 1550 por el convento de Santo Domingo señalara que había ejecutado la traza de la sacristía "como oficial quees de las obras públicas desta cibdad" 19 .

Por desgracia las declaraciones de los testigos no siempre le fueron favorables. En ocasiones no supieron responder afirmativamente a preguntas cuya vera-

17. FERNANDEZ, Martha: Arquitectura y gobierno, op. cit., pp. 30, 48-49 y 52-53.

18. Actas de Cabildo, op. cit., vols. II, III y V, pp. 143, 261 y 147.

19. MARCO DORTA, Enrique: Fuentes para la historia, op. cit., p. 97. 
cidad está comprobada documentalmente. Esas preguntas se relacionan con la figura de Díaz como arquitecto, siendo la más significativa aquella que tendía a demostrar que había sido Maestro Mayor de la Santa Iglesia Mayor. En su caso tampoco respondieron afirmativamente, lo que no implica que no lo fuera. Así parece probarlo el que no contestaran a otra de las preguntas, en las que se les pedía que informasen de las obras que había ejecutado "ansí en la Santa Yglesia mayor como en otras yglesias, ospitales y monasterios y en casas de vecinos y otras obras particulares". Se limitaron a señalar que las había realizado, dándole "perfecion y adornato", pero ninguno las especificó. Constando, sin embargo, que en 1535 intervino en el Hospital de Jesús y en 1550 en el convento de Santo Domingo, no parece que haya que seguir al pie de la letra lo declarado por los testigos. Al respecto sorprende que no mencionaran al Hospital de Jesús, en una de cuyas ventanas aparecía la siguiente inscripción: "Diego Díaz de Lisboa, de nación portuguesa, hizo esta ventana. Año de 1535". Pese a lo notorio de la leyenda no lo citaron, debiendo de haber contribuido a su olvido el que Díaz hubiera llevado a cabo ese trabajo hacía veintisiete años. Por ello, el que no pudieran asegurar que había sido Maestro Mayor de la catedral no implica, necesariamente, que no lo fuera. En ese sentido es más que significativo que la única obra que expresamente mencionaran fuera una casa, habiéndose reseñado no por su especial entidad, sino por el simple hecho de que era de uno de los testigos, el escribano Cuevas.

De todas esas obras, aquella que debiera haber recibido una mayor atención por parte de los testigos, en especial el canónigo Velázquez, es la de la primitiva catedral. Aunque Díaz aseguró que habịa hecho "muchas obras del dicho su oficio en la Santa Yglesia desta cibdad", ni él ni los testigos especificaron en qué consistieron. No obstante, teniendo en cuenta que su oficio era el de cantero, sus intervenciones debieron centrarse en ese campo. En cuanto a su alcance y cronología, partiendo del hecho de que la catedral se concluyó hacia 1532, lo más probable es que fueran trabajos de remodelación, de los que pronto estuvo necesitada la catedral. Al respecto cabe citar las reedificaciones de las portadas y del campanario, tareas llevadas a cabo en 1540 y 154120.

Como cantero trabajó en el Hospital de Jesús, la única obra de la que por ahora se tiene una cierta información, si bien referida sólo a la ventana antes

20. SANDOVAL, Pablo de Jesús y ORDOÑEZ, Jesús: La catedral Metropolitana de México, México, 1938, p. 170.

21. ALAMAN, Lucas: Disertaciones sobre la Historia de la República Mexicana, vol. II, México, 1969, p. 71. Para todo lo concerniente al Hospital de Jesús y en concreto acerca de la ventana labrada por Díaz, cfr. BAEZ MACIAS, Eduardo: El Hospital de Jesús. Historia y documentos sobre su construcción, México, 1982, pp. 26-27. 
citada. Derribada en 1880, Alamán la describe como "una ventana gótica que allí hubo en la misma esquina, con un arco a cada lado, sostenido su cerramiento por un pilar que descansaba sobre la mencionada lápida", en la que figuraba la firma de su artífice 21 . Aunque desaparecida, a tenor de lo descrito por Alamán se podría relacionar con las ventanas geminadas portuguesas. En ese orden de cosas es casi imposible desvincular a Díaz del influjo que la arquitectura portuguesa ejerció sobre la mexicana del siglo XVI, en la que se detectan ecos del manuelino ${ }^{22}$. Como cantero también intervendría en las casas con las que se le relaciona, entre otras la ya citada del escribano Cuevas y las que puso a su cuidado Hernando de Avila. Este último lo nombró el 9 de diciembre de 1553 su mayordomo, encomendándole, como tal, la cobranza y el cuidado de sus casas, a las que atendería como maestro de cantería ${ }^{23}$. De las casas mexicanas de esa época señaló Cervantes de Salazar en 1554 que "las jambas y dinteles no son de ladrillo $\mathrm{u}$ otra materia vil, sino de grandes piedras, colocadas con arte: sobre la puerta están las armas de sus dueños" 24 .

Aunque su trabajo se centraría en la labra de bloques de piedras, no siempre fue así, ya que consta que al menos en una ocasión actuó también como arquitecto. Como ya se comentó, en 1550 declaró que la sacristía del convento de Santo Domingo estaba "traçada para se hazer conforme a la dicha casa e que traçado por este testigo". De todas formas, no parece que Díaz deba ser recordado como arquitecto. Aunque no sea muy científico enjuiciarlo como tal a partir de una sola obra, por lo demás desaparecida, de lo sucedido con la sacristía del convento de Santo Domingo -en ruinas ya, al igual que todo el convento, a principios del XVII- se deduce que sus intervenciones como arquitecto no fueron muy afortunadas. Así debió considerarlas el Virrey Mendoza, ya que en la Memoria de Gobierno dirá a su sucesor que "en lo que toca a los edificios de monasterios y obras públicas ha habido grandes yerros, porque ni en las trazas ni en lo demás no se hacía lo que convenía, por no tener quien las atendiese ni supiese dar orden de ello". Por ello, le recomendó "buscar dos o tres personas que sean buenos oficiales", debiéndose interpretar su consejo como una más que explícita descalificación de la figura de Díaz como arquitecto.

22. Acerca de la influencia de la arquitectura portuguesa sobre la mexicana del siglo XVI sigue siendo válido el estado de la cuestión planteado en 1955 por Pérez Embíd. Cfr. PEREZ EMBIZ, Florentino: El mudejarismo en la arquitectura portuguesa de la época manuelina, Madrid, 1955, pp. 98-100.

23. Archivo General de Notarías, México 1552, s./f. Notaría a cargo de Diego de Isla. Agradezco a mi buen amigo Guillermo Tovar de Teresa el haberme indicado la existencia de este documento.

24. CERVANTES DE SALAZAR, Francisco: México en 1544, México, 1544, p. 56. (Se cita por la edición preparada por Julio Jiménez Rueda, México, 1939). 
De hecho, a Díaz y a todos los maestros de su generación hay que considerarlos como canteros. Como tal se le cita en los documentos, figurando como maestro de arquitectura sólo en los por él redactados: el escrito dirigido en 1553 al Virrey Velasco y la carta enviada en 1562 al príncipe de Eboli. Aunque por esas fechas en el Virreinato de la Nueva España esas dos figuras todavía no se diferenciaban, de lo hasta ahora expuesto se deduce que Díaz debe ser considerado preferentemente como cantero. Ese era el arte que requerían los conquistadores, algunos de los cuales testificaron a su favor. Y ese era el arte que podían ofrecerles los primeros canteros llegados a la Nueva España. Ellos fueron quienes levantaron las primeras construcciones y quienes llevaron a cabo las primeras obras públicas del Virreinato. Con el tiempo algunos pasaron a realizar obras propiamente arquitectónicas. Si en ocasiones, como sucedió con Díaz, no supieron evolucionar, no por ello hay que juzgarlos negativamente. Fueron hijos de su tiempo, habiéndoles tocado en suerte descubrir las canteras con las que se levantaron los grandes monumentos de la arquitectura colonial mexicana y, sobre todo, enseñar a los indígenas a construirlos. Si no hubiera sido nada más que por eso, por haberles dado la regla y el compás, merecerían que se recordasen sus nombres. A tenor de los documentos consultados, el de Díaz parece que hay que vincularlo al de Don Antonio de Mendoza, el Virrey lector de Alberti 25 . Figuras como la suya fueron quienes hicieron realidad sus ideales utópicos, hechos piedras a través de iglesias, hospitales, casas, acequias, puentes y alcantarillas como las labradas por él. Por ello, si no es posible decir que Díaz fue un gran arquitecto, sí cabe señalar que gracias a canteros como él pudo Mendoza hacer de la antigua Tenochtitlan un reflejo de la ciudad ideal de Alberti.

25. Sobre la figura del Virrey Mendoza como lector de Alberti, cfr. TOVAR DE TERESA, Guillermo: La ciudad de México, op. cit 